\title{
Confirmation of Brain Death Using Brain Radionuclide Perfusion Imaging Technique
}

\author{
S. Al-Shammria M. Al-Feelib \\ aDepartment of Medicine, Faculty of Medicine, Kuwait University, Kuwait, ${ }^{b}$ Department of Nuclear Medicine, \\ Mubarak Al-Kabeer Hospital, Jabriya, Kuwait
}

\section{Key Words}

Brain death - Brain radionuclide perfusion - Kuwait

\begin{abstract}
Objective: To determine the reliability of radionuclide cerebral blood perfusion imaging in confirming brain death irrespective of continued heartbeat. Subjects and Methods: Twenty-eight patients (19 male and 9 female, aged 17-63 years) with severe brain injury and fully supported until the final cardiac asystole were included in the study. Two sets of clinical tests aimed at ascertaining brain death in each subject were performed separately for each case within an interval of $24 \mathrm{~h}$. Dynamic, planar and single photon emission computed tomographic (SPECT) brain scintigraphy were also performed after intravenous administration of $550 \mathrm{MBq}(15 \mathrm{mCi})$ technetium-99m hexamethyl propyleneamine oxime. Results: Following the clinical diagnosis of brain death, none of the patients was withdrawn from cardiopulmonary support or had any organ harvested. Dynamic, planar and SPECT imaging performed thereafter did not reveal any intracranial cerebral perfusion in any of the subjects, except in 1 patient where the initial scan showed posterior fossa activity that ceased, in a subsequent scan obtained after $24 \mathrm{~h}$. All of the patients were declared
\end{abstract}

dead only after the emergence of cardiac asystole. Conclusion: The findings indicate that radionuclide brain perfusion imaging is reliable, reproducible, noninvasive and simple to perform for the confirmation of brain death and as such we recommend it as an alternative to exhaustive neurophysiological tests and invasive catheter angiography.

Copyright $\odot 2004$ S. Karger AG, Base

\section{Introduction}

In most Western societies a consensus has evolved over the last three decades that when test requirements for brain death are satisfied, the patient can be declared medically and legally dead, irrespective of continued heartbeat [1-4]. Upon the diagnosis of brain death, when respiratory and other supportive techniques are stopped, the heart stops beating within hours to a few days. This concept of brain death is however still not widely accepted or applied in many countries and societies. In Kuwait, as in most Islamic countries, cessation of cardiac function is the usual criterion for declaration of death, despite the acceptance of brain death by the majority of Islamic jurists at their meeting held in Amman, Jordan, in 1986 [5]. In these countries, in almost all cases the society has

\begin{tabular}{ll}
\hline KARGER & ( ) 2004 S. Karger AG, Basel \\
Fax +4161306 1234 & 1011-7571/04/0135-0267\$21.00/0 \\
$\begin{array}{l}\text { E-Mail karger@karger.ch } \\
\text { www.karger.com }\end{array}$ & $\begin{array}{l}\text { Accessible online at: } \\
\text { www.karger.com/mpp }\end{array}$
\end{tabular}

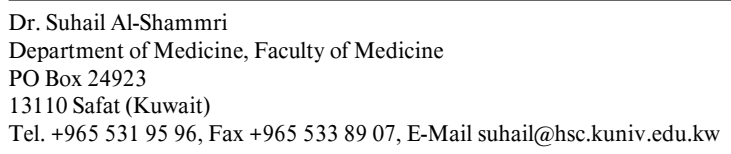


Fig. 1. Planar (a) and SPECT (b) images showing normal cerebral perfusion in supratentorial and infratentorial cerebral compartments.

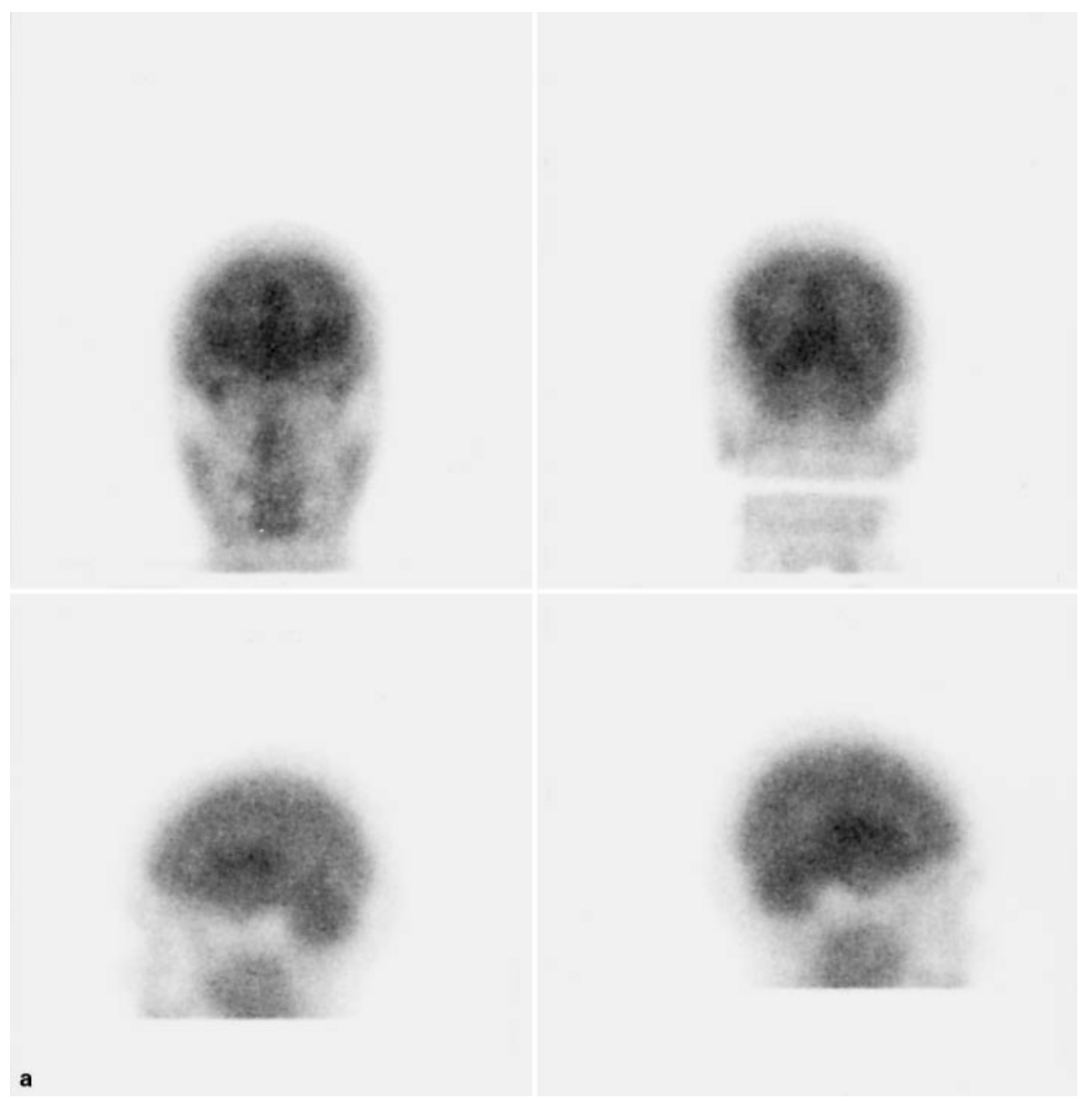

not accepted brain death criteria as sufficient evidence to discontinue supportive care, primarily due to slow cultural acceptance of the concept of brain death. Futile treatment may therefore be continued, consequently slowing down and hindering the procurement of vital organs for transplantation, the demand for which is on the increase. Hence, we decided to prospectively study the reliability and reproducibility of the application of radionuclide brain perfusion imaging technique in confirming the standardized and widely accepted test batteries in the clinical bedside determination of brain death in Kuwait.

\section{Subjects and Methods}

We prospectively examined 28 patients ( 19 male and 9 female) aged $30.5 \pm 11.7$ years (range 17-63) who were admitted to Al-Amiri and Mubarak Al-Kabir Hospitals, Kuwait (two major tertiary care centers affiliated with the Faculty of Medicine, Kuwait University, Kuwait) over a period of 11 years (1992-2001). All of the patients had a devastating brain injury (sufficient to lead to irreversible coma) and as such were suspected to be brain-dead. None of them was a potential organ donor. All the patients received the same standard medical care, including ventilator care and full medical support, and all also had CT scanning of the brain. In no case was supportive treatment withheld because of the presence of signs of brain death. After establishing the usual clinical criteria of brain death, that included absence of cerebral, brainstem and unsupported respiratory functions, radionuclide brain perfusion studies (dynamic, planar and single photon emission computed tomography, SPECT) were performed.

A 5-ml volume of freshly eluated technetium- $99 \mathrm{~m}$ pertechnetate was used to prepare technetium- $99 \mathrm{~m}$ hexamethyl propyleneamine oxime (99m Tc-HMPAO) according to recommendations of the manufacturer (Amersham International PLC, UK). Thin-layer chromatography was done to determine the radiopharmaceutical purity prior to injection. The ${ }^{99 \mathrm{~m}} \mathrm{Tc}-\mathrm{HMPAO}$ was injected within $30 \mathrm{~min}$ of preparation by a physician, who selected the most possible central access.

Dynamic images ( $1 \mathrm{~s} /$ frame for $60 \mathrm{~s}$ ) were acquired, followed by planar static images (anterior, posterior, lateral and vertex views each for $5 \mathrm{~min}$ ) and SPECT (64 projections on single-head ZLC Digitrac camera, Siemens, Erlangen, Germany, each projection for $20 \mathrm{~s})$. The SPECT images were reconstructed using BW 0.55/7 filter and filter 


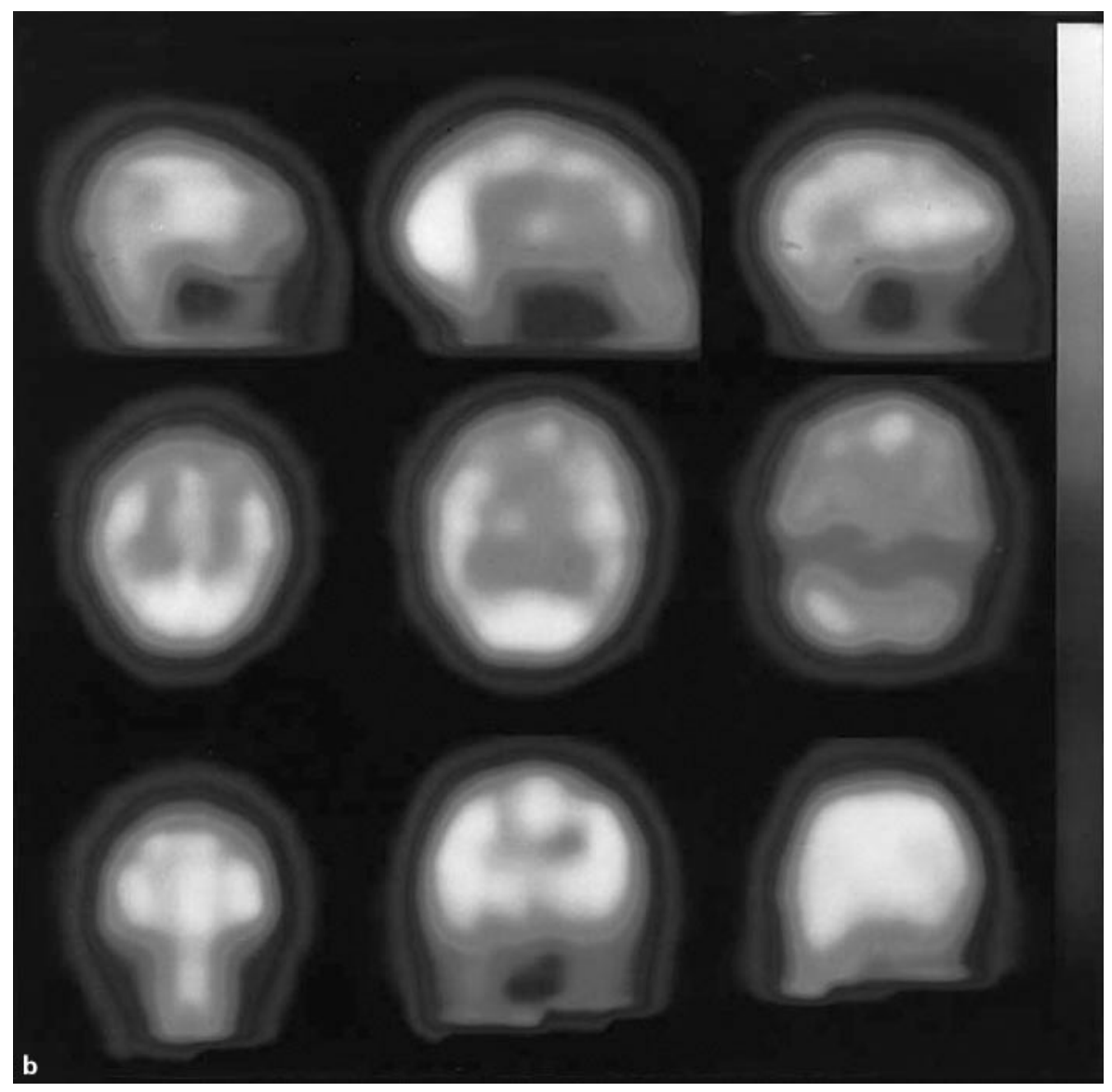

back-projection technique. One-pixel-thick slices (about $11 \mathrm{~mm}$ ) were displayed along with dynamic and static images. Gray and color scales were used to display images on the screen for visual interpretation. The entire procedure lasted about $60 \mathrm{~min}$. Brain death was reported using the combined criteria: absent flow on dynamic study; nonvisualization of sagittal sinus; no uptake of the radiotracer within the brain regions on both planar and SPECT images.

\section{Results}

The demographic data and the etiology of brain death are listed in table 1. Head injury and intracerebral hemorrhage were the most frequent causes of death, each occurring in 10 patients. Other causes were cerebral infarcts in 3 patients, anoxic encephalopathy also in 3 patients, brain tumor and drug overdose, each in 1 patient. All patients were declared brain-dead after satisfying the standard clinical criteria, performed twice at an interval of $24 \mathrm{~h}$.

A normal cerebral blood perfusion image is shown in figure 1 , while that of brain death is shown in figure 2 . In the 28 patients, no cerebral blood flow in dynamic, pla-
Table 1. Demographic data and diagnosis of the patients

\begin{tabular}{rllll}
\hline $\begin{array}{llll}\text { Pa- } \\
\text { tients }\end{array}$ & Sex & Age & Diagnosis \\
\cline { 3 - 4 } & & mean \pm SD & range & \\
\hline 10 & all male & $24.2 \pm 4.42$ & $18-30$ & head trauma \\
10 & $5 \mathrm{~m}, 5 \mathrm{f}$ & $31.6 \pm 11.84$ & $17-59$ & ICH \\
3 & $1 \mathrm{~m}, 2 \mathrm{f}$ & $27.0 \pm 8.54$ & $19-36$ & anoxic encephalopathy \\
3 & $1 \mathrm{~m}, 2 \mathrm{f}$ & $45.3 \pm 15.69$ & $33-63$ & ischemic stroke \\
1 & male & 43 & & brain tumor \\
1 & male & 36 & & drug overdose \\
\hline
\end{tabular}

$\mathrm{ICH}=$ Intracerebral hemorrhage.

nar or SPECT imaging was detected supratentorially and infratentorially, except in 1 patient, who had infratentorial perfusion in the first test that disappeared in the second test done $24 \mathrm{~h}$ later. All patients eventually developed cardiac asystole despite full medical supportive care. 
Fig. 2. Planar (a) and SPECT (b) images showing absence of cerebral perfusion in supratentorial and infratentorial areas consistent with the diagnosis of brain death.

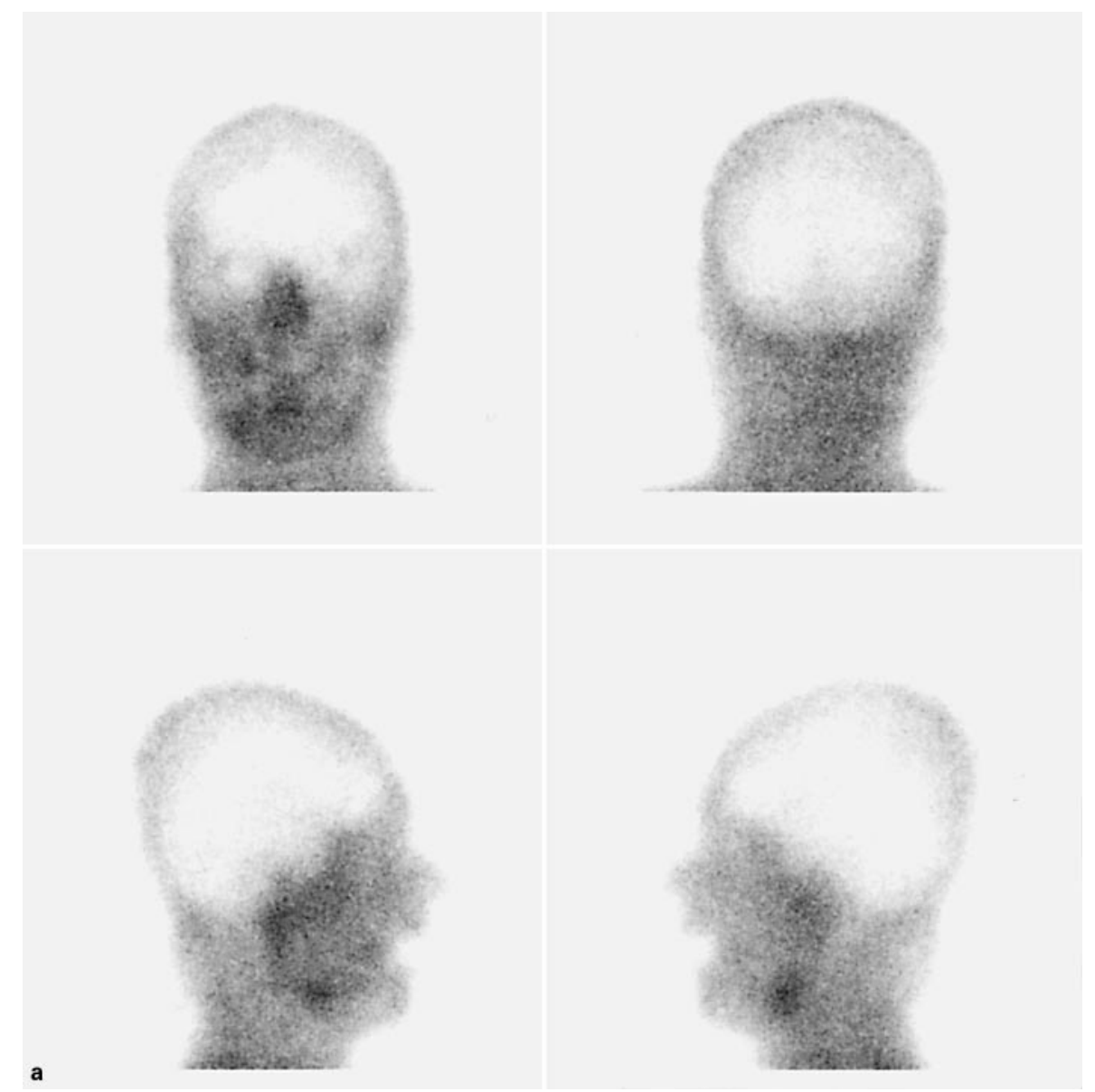

\section{Discussion}

The use of radionuclide cerebral perfusion imaging studies in the confirmation of the clinical criteria for the diagnosis of brain death have been reported previously [6-9]. This study confirms the reliability of dynamic, planar and SPECT imaging for the diagnosis of brain death. We therefore hope that this study will contribute to increase awareness of clinicians in Kuwait and elsewhere, particularly those involved in intensive care and certification of suspected brain death.

Although brain death is essentially a clinical diagnosis, it is desirable to perform laboratory tests to confirm the diagnosis, particularly in cases where the clinical tests cannot be performed safely. These include patients with respiratory failure from causes such as pulmonary edema and adult respiratory distress syndrome where $\mathrm{PaO}_{2}$ may not be raised to a level high enough to safely perform the apnea test; patients with eye injuries that may not be able to react to pupillary, corneal, or vestibulo-ocular reflex testing accurately, and patients with perforated tympanic membranes that cannot safely undergo the ice water caloric test for assessing vestibulo-ocular reflexes.

Confirmatory tests may also be required to shorten the time interval for harvesting organs for possible transplantation. Confirmatory tests are generally neurophysiological or intracranial blood flow studies. Electrophysiological tests include electroencephalography (EEG) [10], brainstem auditory evoked responses (BAER) [11] and somatosensory evoked potentials (SSEP) [12]. The EEG primarily measures hemispheric electrical activity; BAER and SSEP assess brainstem electrical activity. The EEG alone is not an ideal confirmatory test because it may be isoelectric (flat) while the brainstem is still functioning. The BAER and SSEP are less sensitive to metabolic or toxic suppression; however, they sample only a small component of brain function in restricted sensory pathways [13]. Therefore, it is necessary for the three tests to show absence of intracranial electrical activity before brain death can be confirmed [14]. 


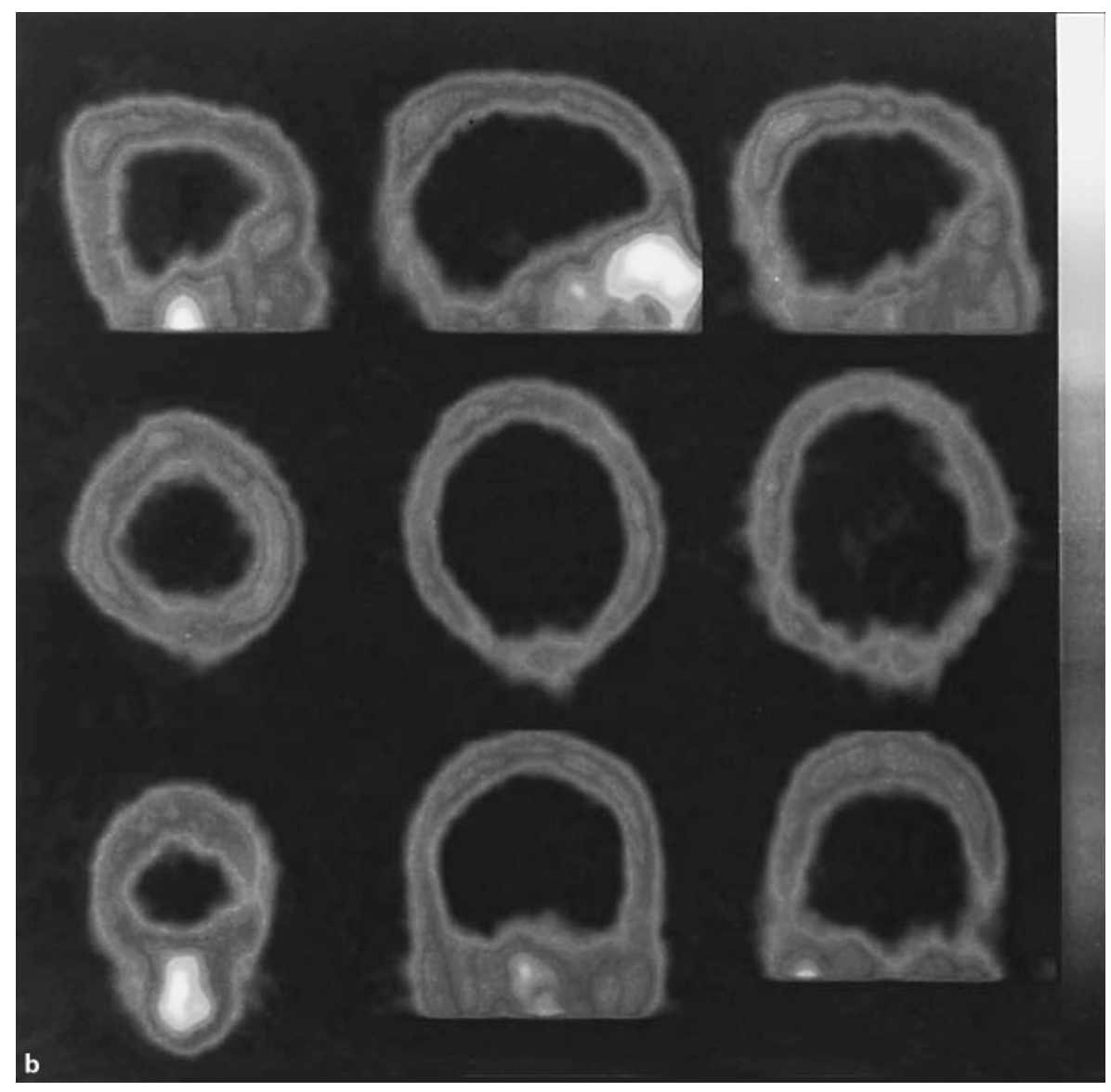

The tests that show the absence of intracranial blood flow include contrast and radionuclide angiography [13, 15], xenon-enhanced CT [16], transcranial Doppler ultrasonography [17] and radionuclide brain perfusion imaging using tracers such as ${ }^{99 \mathrm{~m}} \mathrm{Tc}-\mathrm{HMPAO}$ [18]. These tests are based on the cessation of intracranial blood flow at some time during the process of brain death. Contrast angiography is invasive, not available around the clock and exposes potential donor organs to toxic contrast media [8]. Although xenon-enhanced CT is the most reliable confirmatory test [19], it is not routinely available, due to technical problems associated with the handling of xenon-133, and in addition xenon-133 has low gamma energy $(81 \mathrm{keV})$ and $\mathrm{X}$-radiation $(31 \mathrm{keV})$ that contributes to extracerebral flow [20].

The radionuclide brain perfusion imaging involves a simple intravenous administration of a radiotracer that diffuses across the blood-brain barrier and is extracted by the brain tissue. In the event of brain death, the cerebral tissue fails to extract the radiotracer, hence radioactivity is not detected in the brain thereby leaving an empty box (brain death) appearance (fig. 2). Typical pathology of brain death shows a swelling from a hemispheric lesion that eventually raises the intracranial pressure above the perfusion pressure. The tentorium momentarily protects the cerebellum from the rising pressure, thereby leading to visualization of the posterior fossa when radionuclide brain perfusion is performed early as observed in 1 patient in this study and also previously reported by others $[7,8,21]$.

These findings indicate that posterior fossa perfusion may be present despite definite clinical signs of brain death, probably indicating a stage in the inevitable process of death. In devastating brain injuries, the point at which a decreasing perfusion pressure seriously compromises cerebral circulation to all or a portion of the brain cannot be determined because the changes vary from area to area within the central nervous system and perhaps may explain the discrepancy between compartments [22]. However, this does not imply that in the presence of cere- 
bellar perfusion, brain death based on clinical criteria should lead to withdrawal of life support or harvesting of organs before there is evidence of total lack of intracranial flow in a subsequent scan.

When dynamic phase study does not show sagittal sinus activity, performing planar and SPECT imaging is necessary to confirm the absence of activity in the parenchyma itself. Performing SPECT scan on a routine basis in patients who did not show brain radioactivity on planar images did not offer any additional advantage except when the patient has a scalp wound which could lead to false-positive perfusion in the posterior fossa, then it becomes mandatory to do SPECT scan to establish the absence of parenchymal perfusion.

\section{Conclusion}

This study showed that radionuclide brain perfusion imaging is a simple, reproducible and noninvasive test in the confirmation of brain death. Since the cost of the equipment and the need for specialized training may be prohibitive in underresourced countries, the diagnosis of brain death should rely on the well-established clinical criteria.

\section{Acknowledgment}

The authors wish to acknowledge their appreciation and thanks to Dr. Prem Sharma and Dr. T.R. Swaminathan for statistical assistance and Mr. Suresh Nair for secretarial assistance in preparation of the manuscript.

\section{References}

1 A definition of irreversible coma. Report of the Ad Hoc Committee of the Harvard Medical School to Examine the Definition of Brain Death. JAMA 1968;205:337-340.

2 Conference of Medical Royal Colleges and Their Faculties in the United Kingdom. Diagnosis of brain death. BMJ 1976;ii:1187-1188.

3 Conference of Medical Royal Colleges and Their Faculties in the United Kingdom: Memorandum on the diagnosis of death. BMJ 1997; $\mathrm{i}: 322$.

4 Wijdicks EFM: The diagnosis of brain death. N Engl J Med 2001;344:1215-1221.

5 Daar AS, Al Khitamy AB: Bioethics for clinicians. 21. Islamic bioethics. CMAJ 2001;164: 60-63.

6 Wieler H, Marohl K, Kaiser KP, Klawki P, Frossler H: Tc-99m HMPAO cerebral scintigraphy: A reliable, noninvasive method for determination of brain death. Clin Nucl Med 1993;18:104-109.

7 Valle G, Ciritella P, Bonetti MG, Dicembrino F, Perrone E, Pernas GP: Considerations of brain death on a SPECT cerebral perfusion study. Clin Nucl Med 1993;18:953-954.

8 Reid RH, Gulenchyn KY, Ballinger JR: Clinical use of technetium-99m HM-PAO for determination of brain death. J Nucl Med 1989;30: 1621-1626.
9 Yatim A, Mercatello A, Coronel B, Bret M, Colpart JJ, Moskovtchenko JF, Peyrin JO: $99 \mathrm{~m}$ Tc-HMPAO cerebral scintigraphy in the diagnosis of brain death. Transplant Proc 1991;23:2491.

10 Hughes JR: Limitations of the EEG in coma and brain death. Ann NY Acad Sci 1978;315: 121-136.

11 Goldie WD, Chiappa KH, Young RR, Brooks EB: Brainstem auditory and short-latency somatosensory evoked responses in brain death. Neurology 1981;31:248-256.

12 Hantson P, de Tourtchaninoff M, Guerit JM, Vanormelingen P, Mahieu P: Multimodality evoked potentials as a valuable technique for brain death diagnosis in poisoned patients. Transplant Proc 1997;29:3345-3346.

13 Young GB, Ropper AH, Bolton CF: Coma and Impaired Consciousness: A Clinical Perspective. New York, McGraw-Hill, 1998, pp 6971.

14 Ruiz-Lopez MJ, Martinez de Azagra A, Serrano A, Casado-Flores J: Brain death and evoked potentials in pediatric patients. Crit Care Med 1999;27:412-416.

15 Goodman JM, Heck LL, Moore BD: Confirmation of brain death with portable isotope angiography: A review of 204 consecutive cases. Neurosurgery 1985;16:492-497.
16 Ashwal S, Schneider S, Thompson J: Xenon computed tomography measuring cerebral blood flow in the determination of brain death in children. Ann Neurol 1989;25:539-546.

17 Powers AD, Graeber MC, Smith RR: Transcranial Doppler ultrasonography in the determination of brain death. Neurosurgery 1989 ; 24:884-889.

18 Yoshikai T, Tahara T, Kuroiwa T, Kato A, Uchino A, Abe M, Tabuchi K, Kudo S: Plain CT findings of brain death confirmed by hollow skull sign in brain perfusion SPECT. Radiat Med 1997;15:419-424.

19 Paolin A, Manuali A, Di Paola F, Boccaletto F, Caputo P, Zanata R, Bardin GP, Simini G: Reliability in diagnosis of brain death. Intensive Care Med 1995;21:657-662.

20 Darby JM, Yonas H, Gur D, Latchaw RE: Xenon-enhanced computed tomography in brain death. Arch Neurol 1987;44:551-554.

21 Laurin NR, Driedger AA, Hurwitz GA, Mattar AG, Powe JE, Chamberlain MJ, Zabel PL, Pavlosky WF: Cerebral perfusion imaging with technetium-99m HM-PAO in brain death and severe central nervous system injury. $\mathrm{J}$ Nucl Med 1989;30:1627-1635.

22 Plum F, Posner JB: The Diagnosis of Stupor and Coma, ed 3. Philadelphia, Davis, 1982, p 95. 